\title{
LA REVISIÓN DEL CONTRATO POR LAS PARTES: EL DEBER DE RENEGOCIACIÓN COMO EFECTO DE LA EXCESIVA ONEROSIDAD SOBREVINIENTE
}

\author{
CONTRACT'S REVIEW BY PARTIES: THE RENEGOTIATION'S DUTY \\ CAUSED BY EXCESSIVE ONEROUSNESS OF NEW CIRCUMSTANCES
}

\section{RODRIGO MOMBERG URIBE*}

\begin{abstract}
RESUMEN: El presente trabajo analiza, desde el derecho nacional y comparado, el deber que surge para las partes de renegociar los términos originales del contrato, con el objeto de adaptar las prestaciones correlativas a las nuevas circunstancias en situaciones de excesiva onerosidad sobreviniente. Al efecto, se plantea la hipótesis que en base a las disposiciones legales vigentes, en especial el artículo 1546 del Código Civil, es posible establecer en el Derecho chileno la existencia de dicho deber en caso que el cumplimiento de la prestación de una de las partes haya devenido en excesivamente oneroso, debido a la ocurrencia de circunstancias sobrevinientes e imprevisibles al tiempo de la celebración del contrato.
\end{abstract}

Palabras clave: deber de renegociación, revisión del contrato, excesiva onerosidad sobreviniente.

ABSTRACT: The paper analyzes, through a domestic and comparative law perspective, the duty of the parties to renegotiate the terms of the contract with the aim to adapt them to the new circumstances in cases of excessive onerousness. The author's hypothesis is that, based on currently existing legal provisions, particularly article 1546 of the Civil Code, is possible to state the existence of such a duty in Chilean Law, in cases of supervening and unforeseeable circumstances which have render the performance of the contract excessively onerous for one of the parties.

Key words: duty to renegotiate, contract adaptation, unforeseen circumstances.

\section{INTRODUCCIÓN}

La doctrina nacional ha analizado desde antiguo el tema de la teoría de la imprevisión o excesiva onerosidad sobreviniente, ${ }^{1}$ aun cuando es evidente que su tratamiento es menor si se confronta a la doctrina comparada, sin perjuicio de un resurgimiento del

\footnotetext{
* Licenciado en Ciencias Jurídicas y Sociales, Universidad Austral de Chile. Abogado. LLM en European Private Law, Universidad de Utrecht. Profesor de Derecho Civil, Universidad Austral de Chile. Dirección de correos: Nobelstraat 2a, 3512 EN, Utrecht, Holanda. Correos electrónicos: rmomberg@uach.cl rodrigomomberg@gmail.com Teléfonos de contacto: 31-30-2537405 - 31-06-27168730.

${ }^{1}$ Los términos teoría de la imprevisión, imprevisión contractual y excesiva onerosidad sobreviniente se usarán en este trabajo como sinónimos.
} 
tema durante los últimos años ${ }^{2}$. La insuficiencia doctrinaria puede quizás explicarse en la escasez jurisprudencial relativa a la materia, reflejada en el hecho que la Corte Suprema no ha tenido ocasión de pronunciarse sobre la procedencia o no de dicha teoría en un caso concreto, no obstante ser la jurisprudencia del tribunal superior uniforme en cuanto afirmar la precedencia absoluta del artículo 1545 del Código Civil como norma que establece la intangibilidad del contrato y por tanto la imposibilidad que sus cláusulas sean revisadas por los jueces ${ }^{3}$. La única excepción a la fecha es la sentencia de la Corte de Apelaciones de Santiago de fecha once de noviembre de 2006, la cual es la primera sentencia de un tribunal superior que aplica expresamente la teoría referida ${ }^{4}$.

Sin perjuicio de lo anterior, el objeto de este trabajo no es exponer ni estudiar los supuestos o requisitos necesarios para que opere la teoría de la imprevisión, sino que se centra en el campo de los efectos de la misma, y específicamente, en el deber de renegociación que surgiría para las partes en estos casos ${ }^{5}$. Para el tratamiento de la materia se asumirá entonces que dicha teoría es relevante y aceptada en un sistema jurídico dado y que se han cumplido los requisitos para que proceda su admisión 6 .

En este sentido, ante un cambio sobreviniente de circunstancias por el cual la ejecución de la obligación de una de las partes de un contrato se ha tornado excesivamente onerosa o extremadamente difícil de cumplir, los efectos propuestos por la doctrina o contemplados por aquellos ordenamientos jurídicos que regulan expresamente esta institución, van desde la extinción ${ }^{7}$ del contrato hasta la revisión de sus estipulaciones por un tercero extraño e imparcial (juez o árbitro) ${ }^{8}$. Entre ambos extremos se encuentra

\footnotetext{
${ }^{2}$ En este sentido, PeÑAilillo (2000a) p. 232.

${ }^{3}$ La sentencia clásica que se cita al efecto es la de fecha 10 de enero de 1925, en la cual la Corte Suprema señaló expresamente que "...los tribunales carecen de facultades para derogar o dejar sin cumplimiento la ley del contrato, ya sea por razón de equidad o bien de costumbres o reglamentos administrativos..." Revista de Derecho y Jurisprudencia, t. 23, sec. 1, pág. 423. La referencia a otros fallos puede consultarse en Domínguez et al. (2005) pp. 520-521.

${ }^{4}$ Guillermo Larrain Vial con Serviu Región Metropolitana (2006). Sin embargo, en el caso concreto, los supuestos para la aplicación de la teoría de la imprevisión no se cumplían. Véase MOMBERG (2008) pp. 637-658.

${ }^{5}$ En este trabajo se utilizará el término "deber" en cuanto deber jurídico que impone a un sujeto, en base a la posición que este ocupa, un comportamiento determinado cuya inobservancia acarrea consecuencias jurídicas para el infractor.

${ }^{6}$ En términos generales, los requisitos exigidos por la doctrina chilena para la aplicación de la teoría de la imprevisión pueden sintetizarse en los siguientes: a) Debe tratarse de un acontecimiento imprevisible, es decir, que no es susceptible de ser advertido anticipadamente por las partes al tiempo de celebración del contrato; b) El acontecimiento debe tornar excesivamente onerosa la prestación de una de las partes, de manera que se altere gravemente el sinalagma del contrato, sin que por ello el cumplimiento de la obligación devengue en imposible; c) El hecho imprevisible y que agrava la prestación del deudor, debe ser independiente de su voluntad. Coincidimos además con la opinión que amplía el campo de aplicación de esta doctrina a las obligaciones de cualquier naturaleza, cuyo cumplimiento se encuentre pendiente por causa no imputable al deudor. Véase. PeÑAILILlo, (2000b) pp. 237 y 238.

7 Debido al específico significado legal que el término "resolución" tiene en el derecho de obligaciones chileno, en este trabajo se ha preferido utilizar la expresión "extinción" para referirse al fin o término de la relación contractual entre las partes.

${ }^{8}$ Evidentemente, también existe la posibilidad que la pretensión del deudor sea rechazada y por tanto se mantengan los términos originales del contrato, de lo cual podrá derivarse la ejecución forzada de la obligación o la indemnización de perjuicios por incumplimiento.
} 
la posibilidad de establecer la necesidad de revisión del contrato por las propias partes. En este trabajo el análisis se limita, en los supuestos de inexistencia de una estipulación expresa al efecto, al establecimiento de dicha revisión por medio del deber de las partes de renegociar los términos del contrato cuando la obligación de una de ellas ha devenido en excesivamente onerosa. Por motivos de extensión, se ha excluido el estudio de los casos en que las partes expresamente han pactado la revisión del contrato ante la ocurrencia de determinadas circunstancias.

En suma, se examinarán la buena fe y la naturaleza del contrato como fuentes del deber de renegociación (apartado II), su contenido (apartado III) y los efectos que del éxito o fracaso de las negociaciones se derivan (apartado IV). La hipótesis que se plantea es que, aún a falta de estipulación legal o contractual expresa, cumpliéndose los requisitos para que la excesiva onerosidad sobreviniente opere, surge para las partes, como efecto primario de esta, el deber de renegociación de los términos originales del contrato, con el objeto de adaptarlo a las nuevas circunstancias. Este deber se impone tanto a la parte aventajada o favorecida como a la parte afectada por el cambio sobreviniente de circunstancias, siendo para esta última un requisito o presupuesto necesario para el ejercicio de otros derechos que puedan otorgársele en estos casos.

\section{LA BUENA FE Y LA NATURALEZA DEL CONTRATO O RELACIÓN COMO FUENTE DEL DEBER DE RENEGOCIACIÓN}

La primacía del principio pacta sunt servanda en el proceso codificador del siglo XIX supuso el rechazo a la inclusión de la excesiva onerosidad sobreviniente como causa de extinción o modificación contractual ${ }^{9}$. El referido principio implica la fuerza obligatoria de los contratos (elevada en algunas jurisdicciones al nivel de ley para los contratantes), por la cual las partes deben respetar las obligaciones que válidamente han contraído, teniendo estas fuerza vinculante para ellas y por tanto exigibilidad para su cumplimiento. Esta intangibilidad del contrato supone que ni las partes (con la obvia excepción del mutuo consentimiento) ni el juez pueden variar los términos de un contrato válidamente celebrado, independientemente de cuánto hayan cambiado las condiciones presentes a la celebración del mismo o se haya incrementado la onerosidad o dificultad de su cumplimiento para una de las partes.

La única excepción generalmente admitida a este principio es el caso fortuito o fuerza mayor, es decir, aquella situación en que la prestación de una de las partes ha devenido en imposible debido a la ocurrencia de un hecho sobreviniente imprevisible e independiente de la voluntad de los contratantes.

\footnotetext{
${ }^{9}$ La prevalencia de las ideas sustentadas por la escuela del positivismo científico y las doctrinas del liberalismo económico y la autonomía de la voluntad fueron las principales causas de ello. Así, las dos principales codificaciones europeas, el Code Civil francés y el Código Civil alemán (Bürgerliches Gesetzbuch - $B G B)$ no contemplaron en sus redacciones originales a la imprevisión contractual, rechazando la existencia de la cláusula rebuc sic stantibus desarrollada por los juristas medievales, según la cual la fuerza obligatoria de un contrato depende de la permanencia de las circunstancias bajo las cuales se celebró. Véase ZWEIGERT y KÖTZ (1998), p. 518; y LORENZ (1995) p. 360.
} 
Sin embargo, hoy en día el principio de conservación o preservación del contrato (favor contractus) parece prevalecer en modernas codificaciones las cuales reconocen expresamente la excesiva onerosidad sobreviniente y proveen la revisión del contrato por parte del juez como uno de sus efectos jurídicos ${ }^{10}$. No obstante tal reconocimiento, dichos ordenamientos jurídicos no contemplan de manera explícita el deber de las partes de renegociar las estipulaciones del contrato como efecto de tal situación, al contrario de modernos instrumentos internacionales no vinculantes como los Principios Unidroit sobre Contratos Comerciales Internacionales (en adelante Principios Unidroit), los Principios de Derecho Europeo de Contratos (en adelante PECL por sus siglas en inglés) y el Borrador de Marco común de Referencia (en adelante DCFR por sus siglas en inglés) ${ }^{11}$.

Así, a falta de reconocimiento expreso, en derecho comparado se ha recurrido al principio de buena fe y a la naturaleza del contrato (o en términos generales, de la relación jurídica entre las partes) para justificar la existencia del deber de renegociación en situaciones de excesiva onerosidad sobreviniente. A continuación se examinarán los casos de los Estados Unidos de América y Francia, de manera de incluir en el análisis un sistema de Common Law y otro de Derecho Civil. Además, tal como se explicará, el caso de Francia es especialmente importante para el derecho chileno en esta materia. A estas jurisdicciones se suma el análisis de tres instrumentos normativos internacionales no vinculantes, pero de indudable relevancia: los ya mencionados Principios Unidroit, los PECL y el DCFR.

\section{1) Estados Unidos de AmÉRICA}

En derecho estadounidense, la excesiva onerosidad sobreviniente es tratada en particular bajo la noción de commercial impracticability o simplemente impracticability ${ }^{12}$. Esta doctrina ha sido aceptada desde Mineral Park Land Co. v. Howard ${ }^{13}$, caso en el cual la Corte Suprema de California reconoció que el deudor podía ser excusado cuando el cumplimiento de su obligación se había tornado impracticable, i.e., "solo podía realizarse a un excesivo e irrazonable costo" para aquel. Esta doctrina fue más tarde reconocida en el artículo 2, sección 615 del Uniform Commercial Code (en adelante UCC) y en el comentario a) al parágrafo 261 del Restatement (2nd) of Contracts (en adelante simplemente Restatement). Siguiendo los efectos propios de la doctrina de la frustración del

${ }^{10}$ El ejemplo paradigmático es el $B G B$ alemán, el cual después de la reforma del año 2002 incluyó expresamente en su $\$ 313$ la doctrina de la alteración de la base del contrato (Störung der Geschäftsgrundlag). El Código Civil italiano de 1942 y el nuevo Código Civil holandés (Burgerlijk Wetboek - BW) de 1992 (artículo 6:258) son otros ejemplos.

${ }^{11}$ Así sucede en el caso de Italia, Alemania y Holanda. Sin embargo, la jurisprudencia y la doctrina están contestes que los principios generales de buena fe y la primacía de la conservación del contrato como efecto para estos casos, permiten sustentar la existencia de tal deber. Para un análisis lato de la situación en las referidas jurisdicciones, véase MACARIO, (1996), KARAMPATZOS, (2005), HORN (1985) y BUSCH et al. (2002).

${ }^{12}$ El derecho estadounidense reconoce también la noción de frustration of purpose, en virtud de la cual la prestación debida ha perdido totalmente su utilidad o valor para la parte acreedora, la cual por tanto no tiene interés en perseverar en el contrato.

13172 Cal. 289, 156 P. 458 (1916). 
contrato del Common Law inglés, la jurisprudencia ha establecido que reunidos los requisitos para que opere la excesiva onerosidad, su efecto es la extinción (discharge) del contrato, la cual se produce de manera absoluta y automática, quedando ambas partes liberadas de las obligaciones correlativas, sin ulterior responsabilidad para ellas e independientemente de su voluntad al respecto ${ }^{14}$. Esta alternativa de todo o nada ha sido objeto de críticas por parte de la doctrina norteamericana, ya que no considera como solución una adecuada distribución de los riesgos y por tanto de las pérdidas derivadas de la onerosidad sobreviniente, sino al contrario, implica que una de las partes (ya sea acreedor o deudor, según se acoja o no la pretensión) debe cargar con la totalidad de ellas. También debido a ello, los tribunales han sido extremadamente restrictivos en la aplicación de la doctrina, llegándose a señalar que para excusar al deudor en estos casos, deben reunirse requisitos similares a los de la imposibilidad absoluta de cumplimiento (impossibility) ${ }^{15}$. Sin perjuicio de lo señalado, el UCC y el Restatement, haciéndose cargo de las críticas de la doctrina, contemplan como posibles efectos de la frustración del contrato el ajuste del mismo a través de indemnizaciones o compensaciones mutuas, e incluso la revisión de sus estipulaciones. Así, los comentarios 6 y 7 del artículo 2, sección 615 del UCC, señalan que si ni el sentido común ni la justicia son alcanzados por medio de la extinción del contrato, el caso debe ser examinado a la luz de la buena fe con el propósito de adaptar los términos del contrato. En el mismo sentido, el parágrafo 272 del Restatement (2 $\left.{ }^{\text {nd }}\right)$ of Contracts y sus comentarios, relativo a los efectos de la impracticability, establecen que si la extinción del contrato conlleva a un resultado injusto, el juez está facultado para tomar las medidas que estime pertinentes para evitar dicha injusticia, incluyendo la modificación del contrato. Sin embargo, el reconocimiento de tales alternativas es limitado y no ha tenido mayor acogida en la jurisprudencia. Así, a pesar de la disponibilidad en el UCC y el Restatement de otros remedios distintos a la extinción del contrato, los jueces norteamericanos históricamente se han negado a distribuir entre las partes las pérdidas derivadas de circunstancias sobrevinientes ${ }^{16}$.

Considerando lo anterior, la necesidad de establecer un deber de renegociación en estos casos ha sido desarrollada principalmente por una parte de la doctrina norteamericana en el contexto de la denominada "teoría relacional del contrato". Según esta teoría, planteada en un principio por Ian Macneil ${ }^{17}$, los contratos están inmersos en una matriz de relaciones sociales de la cual no pueden desvincularse. Este aspecto "relacional" se manifiesta con mayor o menos énfasis según la situación particular en que se sitúen los contratantes y el tipo de contrato de que se trate, existiendo por tanto un espectro que él denomina como "discreto-relacional" en el cual pueden calificarse los contratos de acuerdo a si reúnen o no determinadas características, como su plazo de ejecución, el

\footnotetext{
${ }^{14}$ MacKendrick (1991) p. 38. Para un análisis detallado, véase Treitel, (2004) pp. 545 y ss.

15 Para referencias de la jurisprudencia, véase LiTVINOfF (1985-1986) y SOMMER (1974-1975).

16 TRAKMAN (1984-1985) p. 471.

17 MACNEIL (1980). Por razones obvias, este trabajo no pretende exponer ni menos analizar las ideas de Macneil, de manera que solo se harán referencias puntuales a aquellos aspectos que son relevantes para el objeto de este estudio.
} 
establecimiento de relaciones personales entre las partes, la complejidad de las prestaciones, sus efectos respecto de terceros, el interés público involucrado, etc.

En lo pertinente a este trabajo, agrega Macneil que en aquellos contratos que implican una relación jurídica compleja entre las partes manifestada, por ejemplo, a través de vínculos de larga duración y/o dependencia mutua prolongada en el tiempo, la necesaria insuficiencia del acuerdo celebrado entre las partes en relación a su proyección sobre el futuro, genera un deber de cooperación implícito para las partes que implica admitir la flexibilidad y el ajuste de la relación como elementos esenciales para superar las deficiencias del contrato.

Sin embargo, una de las principales falencias de la teoría relacional del contrato ha sido precisamente el no poder entregar una definición jurídica precisa de "contrato relacional", que pueda ser operacionalizada a través de una normativa aplicable a tal especie de contratos ${ }^{18}$. En este sentido, algunos autores han indicado como característica esencial de los contratos relacionales la duración de los mismos, siendo por tanto relacionales aquellos contratos con un prolongado período de ejecución ${ }^{19}$. Finalmente, se ha dicho que contrato relacional sería aquel que implica no solo un intercambio o transacción económica, sino también una relación particular entre los contratantes ${ }^{20}$.

Independientemente de sus imperfecciones, especialmente relativas a la precisión jurídica de sus conceptos, puede sostenerse que la teoría relacional ha sido útil para develar las falencias del derecho de contratos clásico, en especial en relación con la aplicación de sus principios rectores (como el pacta sunt servanda) a relaciones contractuales complejas y que se prolongan en el tiempo, proveyendo así sustentos teóricos para la aplicación de nuevos principios o normas que se hagan cargo de tales falencias.

Así, el contrato es visto como la proyección que las partes hacen de la transacción hacia el futuro, en el cual deberá desarrollarse y surtir sus efectos. Siendo, por definición, el futuro incierto, mientras más se prolongue en el tiempo la ejecución del contrato, más improbable es que dicha proyección sea incompleta o se torne inadecuada para los intereses de las partes.

Además, debido a las implicancias sociales (que incluyen tanto el interés público como de terceros) que de las relaciones jurídicas complejas y de larga duración se derivan, en ellas existen valores implícitos que las partes deben respetar, como la solidaridad contractual (entendida como la lealtad y la consideración mutua de sus intereses por los contratantes), la preservación de la relación y la necesidad de armonización de

18 EISENBERG (1999-2000) pp. 814 y ss., señala que el uso del espectro discreto-relacional es aceptable solo desde un punto de vista sociológico o económico, pero no es útil si se pretende diseñar normas jurídicas que sean aplicables a los contratos relacionales, ya que usando tal concepto, todos los contratos tienen algo de relacional y de discreto, de manera que sería imposible determinar en el caso concreto la normativa aplicable.

${ }^{19}$ Goetz y SCOTT (1981). Sin embargo, tal asimilación ha sido calificada de insuficiente e incompleta. Cfr. EISENBERG (1999-2000) p. 815.

20 Eisenberg (1999-2000) p. 816. El mismo autor señala el problema de esta definición: la inmensa mayoría de los contratos serían relacionales, ya que en general los contratos crean o reflejan, más allá de la prestación económica que constituye su objeto, una relación entre las partes. Por otra parte, la tautología es evidente. 
los conflictos $^{21}$. Como consecuencia de lo anterior, especialmente en contratos de larga duración, es posible establecer la existencia de un deber de negociación en la etapa de ejecución del contrato que exige de las partes cooperación permanente con el fin de preservar su relación y la necesidad de analizar y discutir de buena fe las propuestas de modificación del contrato que haga la parte perjudicada en caso de circunstancias sobrevinientes $^{22}$.

En base a estas ideas, se sostiene que el deber de renegociación puede derivarse de dos premisas: en primer lugar, que las partes deben compartir las ganancias y pérdidas generadas por un cambio imprevisto de circunstancias, las cuales no fueron negociadas al momento de discutirse y celebrarse el contrato ya que derivan de una contingencia o riesgo no contemplado por las partes; y en segundo lugar, que ante la amenaza de extinción de la relación como causa de los eventos sobrevinientes, la necesidad que las partes realicen todos los esfuerzos razonables para preservar y ajustar el contrato a las nuevas circunstancias ${ }^{23}$.

Adicionalmente, otra parte de la doctrina norteamericana ha destacado como fuente del deber de renegociación, la existencia de un principio general de buena fe en materia contractual ${ }^{24}$. Así, se señala que los contratantes se encuentran sometidos al deber de actuar de buena fe, que en la etapa de cumplimiento requiere, siempre que sea necesario, la cooperación de cada parte con el objeto que la otra pueda obtener los beneficios que razonablemente podía esperar del contrato. ${ }^{25}$ De esta manera, cada parte tendría la legítima expectativa que la contraparte actúe en consideración a todos los intereses involucrados en la relación, debiendo cooperar con su preservación si surgen dificultades para cualquiera de ellas ${ }^{26}$.

Este deber ha sido reconocido en el artículo $\$ 1-304$ del UCC, que bajo el título de "obligación de buena fe", provee que todo contrato regido por el UCC impone a las partes la obligación de actuar de buena fe en su cumplimiento y ejecución. Dicha disposición se encuentra en términos similares en el Restatement ${ }^{27}$.

Sin embargo, debe precisarse que los esfuerzos de la doctrina para justificar la existencia de un deber de renegociación no han encontrado acogida en la jurisprudencia norteamericana, la cual ha establecido que no constituye mala de fe ni infracción de obligación legal alguna, la negativa de una de las partes de renegociar el contrato ante el

\footnotetext{
${ }^{21}$ MACNEIL (1980) pp. 52-69.

22 SPEIDEL (1981-1982) p. 404.

23 Ibid. p. 405.

$24 \mathrm{Al}$ efecto, debe recordarse que tradicionalmente los ordenamientos jurídicos del sistema de Common Law han sido renuentes a admitir la existencia de un principio o deber general de buena fe en el derecho de contratos. Si bien puede estimarse que en el presente la buena fe ha ganado lugar y aceptación especialmente en el derecho norteamericano, la resistencia es aún importante en el derecho inglés. Así, en Walford $v$. Miles, la House of Lords determinó que "el concepto de un deber de conducir las negociaciones de buena fe es inherentemente repugnante a la posición adversarial de las partes en el proceso de negociación” (opinión de Lord Ackner).

25 FARNSWORTH, (1963) p. 672.

26 Hillman, p. 7.

27 Parágrafo 205: “Todo contrato impone a las partes los deberes de buena fe y lealtad comercial en su cumplimiento y ejecución”.
} 
requerimiento de la otra, no obstante la existencia de un cambio de circunstancias ${ }^{28}$. Asimismo, en otro fallo se estableció que ante la existencia de un contrato válidamente concluido, negarse a renegociar el precio y en cambio solicitar la ejecución forzada de la contraprestación no constituye mala fe ni incumplimiento del contrato. ${ }^{29}$ Por último, se ha fallado que las doctrinas de la buena fe y la lealtad comercial establecidas en el UCC, no obligan a una parte a aceptar cambios materiales en los términos del contrato o a asumir obligaciones que modifiquen o contradigan cláusulas expresas del contrato ${ }^{30}$.

\section{2) FRANCIA}

Tomando en consideración que el inciso tercero del artículo 1134 y el artículo 1135 del Code Civil francés son las fuentes directas del artículo 1546 de nuestro Código Civil $^{31}$, norma que como se explicará más adelante, es la esencial en la materia objeto de este trabajo, el análisis de la jurisprudencia y doctrina francesa relativa al deber de renegociación es especialmente relevante.

La procedencia de la teoría de la imprevisión (théorie de l'imprévision) y por consiguiente, la posibilidad de la revisión del contrato en el Derecho Civil francés para el caso no previsto en el Code Civil en que la obligación de una de las partes, aun cuando técnicamente posible de cumplir, devengue en excesivamente onerosa, ha sido constantemente denegada por la Cour de Cassation francesa ${ }^{32}$. La sentencia clásica al efecto es la recaída en el denominado caso del Canal de Craponne, en la cual la Cour negó la posibilidad de revisar y adaptar un contrato celebrado en el siglo XVI, cuyo precio (una renta periódica) se había tornado evidentemente irrisorio cuando el caso fue llevado ante los tribunales trescientos años después. Revocando las resoluciones del tribunal de primera y segunda instancia, que habían dado lugar a una revisión del precio basada en la equidad (équité), el tribunal de casación estableció que "en virtud de ser el artículo 1134 (del Code Civil) una norma general y absoluta, no corresponde a los tribunales, no obstante lo justa que su decisión les pueda parecer, tomar en consideración el transcurso del tiempo u otras circunstancias con el objeto de modificar los contratos celebrados por las partes" 33 . Una importante parte de la doctrina civil clásica es también contraria a la revisión judicial del contrato por esta causa: "sería extremadamente peligroso dejar el contrato a la discreción del juez; su intervención en la ejecución

\footnotetext{
${ }^{28}$ Louisiana Power \& Light Co. v. Allegheny Ludlum Industries, Inc.

29 Missouri Pub. Serv. Co. v. Peabody Coal Co. En el mismo sentido, Ehredt Underground Inc. v. Commonwealth Edison Co.

${ }^{30}$ ADT Security Services Inc. v. Premier Home Protection Home Inc.

31 FUEYO (1990) p. 179.

32 En derecho administrativo la situación es diversa, ya que el Conseil d'État (tribunal superior en esta materia) ha admitido desde 1916, en el denominado caso Gaz de Bourdeaux (C.E., 30 de marzo 1916), la aplicación de la teoría de la imprevisión a los contratos administrativos. Basada en el principio de continuidad del servicio público, ella se manifiesta en la invitación a las partes a renegociar los términos del contrato. A falta de acuerdo, el juez administrativo está facultado para fijar una indemnización a favor de la contraparte de la administración pública, sin revisar los términos del contrato. Véase GHESTIN (2001) et al. p. 308.

33 Civ. 6 de marzo 1876, DP 1876.I.197. La doctrina del fallo ha sido confirmada con posterioridad en reiteradas ocasiones. Véase CAPITANT et al. (2000) pp. 123-132.
} 
de las convenciones por medio de sus sentimientos personales de equidad e interés general arruinaría el contrato y pondría en peligro el sistema económico en su totalidad, destruyendo la seguridad de las relaciones contractuales" 34 .

Sin embargo, una reciente pero consistente jurisprudencia de la Cour de Cassation francesa ha establecido la existencia de un deber de renegociar en los casos en que la obligación de una las partes ha devenido en excesivamente onerosa, alterando de manera radical el equilibrio contractual ${ }^{35}$.

Así, sin admitir en toda su extensión la aplicación de la teoría de la imprevisión, la Cour, primero por medio de su Chambre commerciale y más tarde también a través de la Chambre civile, ha establecido que si en virtud de circunstancias graves e imprevistas se produce una alteración severa en el equilibrio contractual, el principio de buena fe y el deber de lealtad que se deben las partes dan lugar al deber de la parte aventajada de renegociar el contrato a requerimiento de la parte afectada por el cambio de circunstancias. El fundamento legal está dado principalmente por el inciso tercero del artículo 1134 del Code Civil, que impone el deber de buena fe en la ejecución de los contratos, y el artículo 1135 del mismo Código, que señala que los contratos no obligan solamente a lo expresamente estipulado, sino también a todo aquello que según la equidad pueda atribuírsele según su naturaleza ${ }^{36}$. En este sentido, se ha fallado que el contratante que en contra de las exigencias de la buena fe se niega a renegociar los términos del contrato durante la etapa de cumplimiento del mismo, es responsable de los perjuicios que tal negativa produzca a su contraparte ${ }^{37}$.

En sus decisiones, la Cour ha precisado que el desequilibrio contractual debe producirse precisamente como consecuencia de un cambio imprevisto y sobreviniente de circunstancias durante el período de ejecución del contrato. Un desequilibrio presente al momento de la celebración del contrato no puede ser considerado como contrario a la buena fe, en virtud del principio de libertad contractual y la presunción de igualdad entre las partes, que siguen siendo pilares del derecho de contratos ${ }^{38}$. En este sentido, la Cour ha distinguido entre un desequilibrio estructural del contrato (déséquilibre structurel du contrat) y la modificación imprevista de las circunstancias económicas (modifica-

\footnotetext{
${ }^{34}$ MAZEAUd et al. (1996) p. 856.

35 "Arrêt Huard" (1992), "Arrêt Chevassus-Marge" (1998), Cass. civ. 16 de marzo 2004, CA Nancy $2^{\text {nd }}$ Ch. Com. 26 de septiembre 2007.

${ }^{36}$ Artículo 1134: Los acuerdos legalmente formados tendrán fuerza legal entre quienes los hayan efectuado. Podrán ser revocados por mutuo consentimiento, o por las causas que autoriza la ley. Deberán ser ejecutados de buena fe. Artículo 1135: Los acuerdos obligarán no solo a lo expresado en ellos, sino también a todas las consecuencias que la equidad, la costumbre o la ley atribuyan a la obligación según su naturaleza. Traducción disponible en http://195.83.177.9/code/liste. phtml?lang=esp\&c=41\&r=1810 (fecha de consulta: 13 de julio de 2009).

37 Arrêt Huard" (1992), "Arrêt Chevassus-Marge" (1998).

${ }^{38}$ Cass. civ. 16 de marzo 2004. En el comentario del fallo, MAZEAUd (2004) pp. 1757 y 1758, destaca que la regla general en el derecho francés es la validez de los contratos lesionarios, sin perjuicio que la Cour ha encontrado sustento en las nociones de causa y violencia económica para anular contratos que presentaban un desequilibrio serio en las contraprestaciones al momento de su celebración. Al efecto, señala también que legislación especial como la de consumo y libre competencia han adoptado un enfoque diverso en esta materia.
} 
tion imprévue des circonstances économiques). En el primer caso, la parte afectada por el desequilibrio no tiene el derecho a poner término al contrato o solicitar la renegociación del mismo, y debe cumplir con su prestación sin perjuicio de las dificultades u onerosidad que tal cumplimiento le imponga ${ }^{39}$. La referencia que la Cour ha hecho a la imprevisibilidad de las circunstancias modificatorias del equilibrio contractual es lo que ha permitido sostener a la doctrina que la jurisprudencia citada constituye efectivamente una excepción al principio de la fuerza obligatoria del contrato consagrado en el artículo 1134 del Code Civil y al rechazo a la revisión contractual en casos de imprevisión ${ }^{40}$.

Sin perjuicio de lo anterior, debe precisarse que el deber de renegociación es considerado por la Cour como el único y último recurso de la parte perjudicada en estos casos, sin que se le conceda derecho a solicitar la extinción del contrato o la revisión del mismo por parte del tribunal. En virtud de lo anterior, los efectos del fracaso de las negociaciones tienen un carácter extremadamente restringido, lo que en definitiva conlleva a que la posición de la parte perjudicada por el cambio de circunstancias siga siendo débil.

Siguiendo la línea de la jurisprudencia mencionada, los proyectos de reforma al Code Civil han optado por proponer una regulación expresa del deber de renegociación en casos de imprevisión. Así, el Ante-Proyecto para la reforma del Derecho de Obligaciones $y$ de la Prescripción, preparado por un grupo de destacados académicos bajo la dirección del profesor Pierre Catala (en adelante, el Proyecto Catala), incluye en su propuesta el reconocimiento de manera restringida de la excesiva onerosidad sobreviniente ${ }^{41}$. El artículo 1135-1 del Proyecto dispone que en el caso de contratos de ejecución diferida o sucesiva las partes pueden estipular la renegociación del contrato, cuando en virtud de circunstancias sobrevinientes, se produce una alteración del equilibrio entre las prestaciones, perturbando la relación al extremo de hacer desaparecer el interés de una de las partes en el contrato ${ }^{42}$. A falta de cláusula expresa, la parte que ha perdido interés en el contrato puede solicitar al presidente del tribunal de primera instancia que ordene la renegociación de los términos del contrato (artículo 1135-2) ${ }^{43}$. Por último, las negociaciones deben realizarse de buena fe y su fracaso da derecho a las partes a terminar (résilier) el contrato, sin derecho al reembolso de gastos o la indemnización de perjuicios, salvo que exista mala fe (artículo 1135-3) ${ }^{44}$.

Sin embargo, el referido Ante-Proyecto ha sido objeto de críticas por parte de autores franceses y foráneos, debido a su carácter conservador y falta de concordancia

\footnotetext{
39 Por supuesto, a menos que exista otro tipo de excusa, como un vicio del consentimiento.

${ }^{40}$ Véase Mazeaud (2004) p. 1756.

41 Disponible en español en http://www.henricapitant.org/sites/default/files/Version_espagnole.pdf (fecha de consulta: 13 de julio de 2009).

42 Art. 1135-1: Dans les contrats à exécution successive ou échelonnée, les parties peuvent s'engager à négocier une modification de leur convention pour le cas où il adviendrait que, par l'effet des circonstances, l'équilibre initial des prestations réciproques fût perturbé au point que le contrat perde tout intérêt pour l'une d'entre elles.

43 Artículo 1135-2: A défaut d'une telle clause, la partie qui perd son intérêt dans le contrat peut demander au président du tribunal de grande instance d'ordonner une nouvelle négociation.

${ }^{4}$ Artículo 1135-3: Le cas échéant, il en irait de ces négociations comme il est dit au chapitre 1er du présent titre. Leur échec, exempt de mauvaise foi, ouvrirait à chaque partie la faculté de résilier le contrat sans frais ni dommage.
} 
con tendencias modernas relativas a la materia en derecho comparado ${ }^{45}$. En particular respecto de las normas relativas a la imprevisión, se ha objetado su inutilidad y redundancia, ya que a la luz del principio de libertad contractual consagrado en el artículo 1134 del Code, parece absolutamente innecesario conferir expresamente a través de una norma legal el derecho a las partes de pactar una cláusula de renegociación del contrato. El efecto de tal norma podría incluso ser el opuesto al deseado, ya que podría interpretarse en el sentido que tales cláusulas solo serían válidas en contratos de ejecución diferida o escalonada ${ }^{46}$. En el mismo sentido, el informe de la Cour de Cassation sobre el Ante-Proyecto critica lo restringido de la regulación propuesta, en especial al no considerar la posibilidad que el juez intervenga en el contrato por medio de su adecuación a las nuevas circunstancias o su extinción en los términos que considere apropiados para el caso en particular ${ }^{47}$.

Basado en el Proyecto Catala (que puede considerarse como una iniciativa académica), la Chancellerie (Ministerio de Justicia francés) ha presentado otro proyecto de reforma, limitado al derecho de obligaciones ${ }^{48}$. Dicho proyecto señala en su artículo 136 que en caso que un cambio de circunstancias imprevisible e insuperable torne la ejecución de la prestación excesivamente onerosa para una de las partes, que no haya consentido en asumir el riesgo, esta podrá demandar la renegociación del contrato a su contraparte, sin perjuicio de continuar obligada a ejecutar la prestación durante el período de renegociación. Agrega la norma que en caso de fracasar las negociaciones, el juez puede, siempre que las partes lo acuerden, adaptar el contrato, o en su defecto, ponerle término con la fecha y condiciones que estime pertinentes para el caso particular ${ }^{49}$. La norma es un avance en relación a la contemplada en el Proyecto Catala, ya que elimina le referencia superflua al acuerdo de las partes y concede, sin necesidad de aquel, el derecho a la parte perjudicada por el cambio de circunstancias de demandar la renegociación de los términos del contrato. Sin embargo, la propuesta sigue siendo conservadora en cuanto a las facultades del juez en caso de fracaso de las negociaciones, ya que este solo podrá adaptar el contrato si las partes le confieren tal facultad. Como contrapartida, si tal acuerdo no existe, el juez tiene amplias facultades para decretar la extinción del contrato con la fecha y en las condiciones que estime más convenientes según el caso concreto. Ello implica entre otras cosas, determinar el efecto retroactivo o no de la extinción del

\footnotetext{
45 Hondius (2007).

46 Fauvarque-Cosson, y Mazeaud (2007) p. 532.

47 Rapport du groupe de travail de la Cour de cassation Sur l'avant-projet de réforme du droit des obligations et de la prescription, 15 juin 2007; disponible en http://www.courdecassation.fr/institution_1/ autres_publications_discours_2039/discours_2202/travail_cour_10699.html (fecha de consulta: 13 de julio de 2009)

48 Disponible en http://www.dimitri-houtcieff.fr/files/projet_droit_des_contrats_blog8_2_.pdf. (fecha de consulta: 13 de julio de 2009). Este proyecto debería comenzar a ser analizado por el Parlamento durante el segundo semestre del año 2009

${ }^{49}$ Art. 136 : Si un changement de circonstances, imprévisible et insurmontable, rend l'exécution excessivement onéreuse pour une partie qui n'avait pas accepté d'en assumer le risque, celle-ci peut demander une renégociation à son cocontractant mais doit continuer à exécuter ses obligations durant la renégociation. En cas de refus ou d'échec de la renégociation, le juge peut, si les parties en sont d'accord, procéder à l'adaptation du contrat, ou à défaut y mettre fin à la date et aux conditions qu'il fixe.
} 
contrato, su continuación por un plazo determinado, las prestaciones mutuas o indemnizaciones que deban hacerse las partes, etc. Por último, con el objeto de evitar que el requerimiento de renegociación sea utilizado solo como un medio para dilatar la ejecución del contrato, la parte que la demanda continúa a obligada a cumplir con su prestación durante el período de renegociaciones.

\section{3) Modernos instrumentos nORMATIVOS INTERNACIONALES NO VINCULANTES}

Al contrario de las legislaciones nacionales, modernos textos normativos generados con la idea de armonizar o unificar principalmente el derecho de contratos en Europa o a nivel internacional, contienen normas que establecen y regulan específicamente el deber de renegociación como efecto de la excesiva onerosidad sobreviniente. Así sucede con tres de los más importantes instrumentos en esta materia, los Principios UNIDROIT, los (PECL) y el DCFR, que en términos similares se refieren al tema ${ }^{50}$.

Así, los Principios Unidroit proveen en su artículo 6.2.3 que en caso de excesiva onerosidad la parte perjudicada puede solicitar a la otra la renegociación del contrato. Dicha solicitud debe efectuarse sin demora injustificada y con indicación de los fundamentos en que se basa. En caso que las partes no lleguen a acuerdo en un plazo razonable, cualquiera de ellas puede solicitar al tribunal la extinción o adaptación del contrato. Aun cuando los términos de la norma no son en principio imperativos, la obligatoriedad de la renegociación es evidente ya que el derecho a requerir la intervención del tribunal está condicionado a la incapacidad de las partes de llegar a un acuerdo previo sobre la adaptación del contrato ${ }^{51}$.

Por otra parte, los PECL estipulan que las partes están obligadas a negociar la adaptación del contrato en caso que el cumplimiento del contrato devengue en excesivamente oneroso. Asimismo, si las partes no alcanzan acuerdo en un término razonable, el juez posee amplias facultades para terminar o adaptar el contrato, estableciéndose ade-

\footnotetext{
${ }^{50}$ Este trabajo, por razones obvias, no pretende dar cuenta de la naturaleza, orígenes y desarrollo de estos instrumentos ni del proceso de armonización del derecho comercial internacional o europeo. Solo precisaremos que a juicio del autor se trata de textos soft law o derecho no vinculante, entendiendo por tal aquella normativa que si bien no tiene fuerza legal vinculante para sus destinatarios, pretende producir, directa o indirectamente, efectos prácticos como fuente de referencia o mediante su aplicación voluntaria por parte de tales destinatarios. Cfr. SENDEN (2005).

51 Efectos de la "excesiva onerosidad"(hardship).

(1) En caso de "excesiva onerosidad" ( hardship), la parte en desventaja puede reclamar la renegociación del contrato. Tal reclamo deberá formularse sin demora injustificada, con indicación de los fundamentos en los que se basa.

(2) El reclamo de renegociación no autoriza por sí mismo a la parte en desventaja para suspender el cumplimiento.

(3) En caso de no llegarse a un acuerdo dentro de un tiempo prudencial, cualquiera de las partes puede acudir a un tribunal.

(4) Si el tribunal determina que se presenta una situación de "excesiva onerosidad" (hardship), y siempre que lo considere razonable, podrá:

(a) resolver el contrato en fecha y condiciones a ser fijadas; o

(b) adaptar el contrato con miras a restablecer su equilibrio.
} 
más de manera expresa la facultad de condenar en perjuicios a la parte que se negó a negociar o rompió de mala fe las negociaciones ${ }^{52}$.

De manera semejante, el DCFR establece también como uno de los requisitos para que la parte perjudicada por un cambio de circunstancias pueda solicitar al juez el término o la adaptación del contrato, el que dicha parte haya procurado, razonablemente y de buena fe, llegar a un acuerdo razonable y equitativo para adaptar los términos de la obligación a las nuevas circunstancias ${ }^{53}$.

Como puede apreciarse, los textos citados son semejantes en el tratamiento general de la materia, estableciendo como primer derecho y deber de la parte perjudicada en caso de excesiva onerosidad sobreviniente, ya que es requisito para la intervención del juez, la facultad de requerir a la otra la renegociación del contrato con el objeto de adaptarlo a las nuevas circunstancias. Tanto la solicitud de renegociación como las negociaciones mismas, están sujetas a los principios de buena fe (art. 1.7 Principios Unidroit, art. 1:201 PECL y arts. I - 1:103 y III - 1:103 DCFR) y al deber de cooperación (art. 5.3 Principios

52 Artículo 6:111: Cambio de circunstancias

(1) Las partes deben cumplir con sus obligaciones, aun cuando les resulten más onerosas como consecuencia de un aumento en los costes de la ejecución o por una disminución del valor de la contraprestación que se recibe.

(2) Sin embargo, las partes tienen la obligación de negociar una adaptación de dicho contrato o de poner fin al mismo si el cumplimiento del contrato resulta excesivamente gravoso debido a un cambio de las circunstancias, siempre que:

(a) Dicho cambio de circunstancias haya sobrevenido en un momento posterior a la conclusión del contrato.

(b) En términos razonables, en el momento de la conclusión del contrato no hubiera podido preverse ni tenerse en consideración el cambio acaecido.

(c) A la parte afectada, en virtud del contrato, no se le pueda exigir que cargue con el riesgo de un cambio tal de circunstancias.

(3) Si en un plazo razonable las partes no alcanzan un acuerdo al respecto, el juez o tribunal podrá:

(a) Poner fin al contrato en los términos y fecha que considere adecuado.

(b) $\mathrm{O}$ adaptarlo, de manera que las pérdidas y ganancias resultantes de ese cambio de circunstancias se distribuyan entre las partes de forma equitativa y justa.

En cualquiera de los casos, el juez o tribunal podrá ordenar que la parte que se negó a negociar o que rompió dicha negociación de mala fe, proceda a reparar los daños causados a la parte que sufrió dicha negativa o dicha ruptura.

53 III.-1:110: Modificación o extinción por el juez en caso de cambio de circunstancias

(1) Una obligación debe ser ejecutada aun cuando su cumplimiento sea más oneroso, ya sea porque los costos del cumplimiento se han incrementado o porque el valor de la contraprestación ha disminuido. (2) Sin embargo, si debido a un cambio excepcional de circunstancias, el cumplimiento de una obligación contractual o de una obligación derivada de un acto jurídico unilateral se torna tan onerosa que sería manifiestamente injusto obligar al deudor a cumplir, el juez puede: (a) modificar la obligación con el objeto de hacerla razonable y equitativa de acuerdo a las nuevas circunstancias; o (b) declarar la extinción de la obligación con la fecha y en los términos que estime convenientes. (3) El párrafo (2) se aplicará solo si (a) el cambio de circunstancias ocurre después de contraerse la obligación; (b) el deudor no tomó en cuenta en dicho momento, ni podía razonablemente esperarse que así lo hiciese, la posibilidad o magnitud de tal cambio de circunstancias; (c) el deudor no asumió ni puede razonablemente considerarse que haya asumido los riesgos de tal cambio de circunstancias; y (d) el deudor ha intentado, razonablemente y de buena fe, lograr por medio de la negociación, una modificación razonable y equitativa de la obligación. Traducción del autor. La versión completa del DCFR puede consultarse en www.law-net.eu/en index.htm (fecha consulta: 13 de julio de 2009). 
Unidroit, art. 1:202 PECL y art. III - 3:104 DCFR) en base a los cuales pueden determinarse a su vez conductas específicas que deben ser observadas por las partes durante tal período. Estas conductas (que se concretan en derechos y deberes) serán examinadas detalladamente en los párrafos dedicados al contenido del deber de renegociación.

\section{4)}

\section{CHILE}

En relación a la posibilidad de establecer la existencia de un deber de renegociación en casos de imprevisión contractual, el autor estima que las ideas expuestas en derecho comparado para justificar tal deber son perfectamente aplicables a nuestro ordenamiento y permiten por tanto argumentar a favor de su admisibilidad en el derecho chileno. Al efecto, para evitar reiteraciones, se expondrán algunas solo algunas consideraciones adicionales.

Así, aun cuando el Código Civil no contiene una norma expresa que consagre de manera general el principio de buena fe, es comúnmente aceptada por la doctrina su vigencia como tal no solo en materia de contratos sino respecto de todo el ordenamiento jurídico ${ }^{54}$.

Sin embargo, la carencia de una norma general es suplida por su consagración específica en diversas materias, entre las cuales destaca para efectos de este trabajo, la disposición del artículo 1546 relativa a la ejecución de los contratos de buena fe. La referida norma dispone que "Los contratos deben ejecutarse de buena fe, y por consiguiente obligan no solo a lo que en ellos se expresa, sino a todas las cosas que emanan precisamente de la naturaleza de la obligación, o que por la ley o la costumbre pertenecen a ella". No obstante el texto expreso de la norma parece restringir la aplicación de la buena fe a la etapa del cumplimiento, se entiende que esta debe extenderse a todo el íter contractual, incluidas las tratativas preliminares, lo mismo que a la interpretación del contrato. En concreto, la buena fe exige a los contratantes un comportamiento recíproco basado en la lealtad, la honestidad y la consideración de los intereses de la contraparte. Este principio general ha sido considerado fuente de diversos deberes de conducta para los contratantes, como los de cooperación, información y diligencia, entre otros.

Debido a que la imprevisión contractual se considera relevante si acaece durante la etapa de cumplimiento del contrato, la norma del artículo 1546 puede aplicarse sin reparos a tal caso ${ }^{55}$. Así, situada en el período de ejecución del contrato, la buena fe permite determinar la extensión del mismo en cuanto al correcto cumplimiento de las obligaciones de las partes más allá del tenor literal de la convención. Esta determinación afecta a ambas partes: el acreedor puede reclamar que la prestación no sea inferior a lo que la buena fe demanda o bien puede ver limitada su pretensión cuando el deudor cumpla según lo que la buena fe exige; y por otra parte, el deudor puede ser exigido a más de lo que literalmente reza el contrato o bien solicitar que su cumplimiento se limite o reduzca, según los parámetros expresados ${ }^{56}$. En otras palabras, la buena fe actúa

\footnotetext{
54 PeÑailillo (2003) p. 52.

55 PeÑAilillo (2000a) p. 232

56 FUEYO (1990) p. 182
} 
en la etapa de ejecución del contrato como un parámetro al cual deben sujetarse las partes y que permite determinar aquello a lo que está obligado el deudor.

A partir de estas ideas, puede justificarse el nacimiento de un deber de renegociación cuando la ejecución del contrato se torna en exceso perjudicial para el obligado, debido al acaecimiento de circunstancias imprevisibles al tiempo de la contratación que han modificado sustancialmente el contexto o entorno en el cual se negoció y se celebró el acuerdo entre las partes. Derivado de la buena fe aparece aquí el deber de cooperación que se deben mutuamente los contratantes y que implica que ambos deben tener en consideración no solo su propio interés en el cumplimiento del contrato, sino también el de la contraparte, de manera de alcanzar el objetivo o fin común que se buscaba al celebrar el contrato, o lo que es lo mismo, los beneficios recíprocos derivados del acuerdo. De este modo, puede sostenerse que, cumpliéndose los requisitos de la excesiva onerosidad sobreviniente, contraviene la buena fe y por tanto al deber de cooperación mutua que corresponde a los contratantes, la conducta de la parte que se niega a la readecuación del contrato e insiste en exigir la prestación según los términos literalmente establecidos.

En definitiva, los conceptos de ejecución de buena fe, cooperación, lealtad comercial y solidaridad contractual a los cuales se han hecho referencia en párrafos anteriores, no pueden considerarse extraños a nuestro derecho si lo consideramos desde una perspectiva contemporánea. Al efecto, se ha sostenido que la imposición a las partes de diversos deberes de conducta derivados del principio general de buena fe es el reflejo de una tendencia internacional hacia una mayor moralización de las relaciones contractuales ${ }^{57}$, a la cual, según nuestra opinión, nuestro ordenamiento no puede permanecer ajeno.

\section{CONTENIDO DEL DEBER DE RENEGOCIACIÓN}

Establecida la existencia de un deber de renegociación, reviste importancia la determinación de su contenido, ya que este frecuentemente aparece como difuso y no especificado. Así, las normas e incluso las estipulaciones de las partes que establecen tal deber solo efectúan referencias generales a principios u otros deberes como la buena fe, la lealtad negocial, la cooperación, etc. Debido a lo anterior, a continuación se analizará en particular la conducta que las partes deben observar en el marco de este deber, y por tanto los derechos y obligaciones a que están sujetos.

\section{1) El DEBER de RENEGOCIAR DE BUENA FE. CONDUCTAS ESPECÍfiCAS QUE DEBEN OBSERVAR LOS CONTRATANTES}

La aplicación del principio de buena fe al proceso de renegociación implica una serie de conductas particulares que deben ser observadas por ambas partes durante este período.

En primer lugar, la parte afectada por la excesiva onerosidad debe requerir la renegociación del contrato en el más breve plazo y sin demora injustificada. La naturale-

57 Vogenauer y KLEINHEISTERKAMPF (2009) pp. 165-167. 
za de la obligación que se ha tornado excesivamente onerosa y de las circunstancias que han causado tal onerosidad son los criterios esenciales para determinar en el caso particular la oportunidad del requerimiento. Tal requerimiento además debe estar adecuadamente fundado en cuanto a la existencia de las circunstancias sobrevinientes que afectan el contrato y la manera en que tales circunstancias transforman la prestación de la parte afectada en excesivamente onerosa, de modo que la contraparte cuente con información suficiente para analizar el derecho de la otra a solicitar la renegociación ${ }^{58}$.

En el mismo sentido, propuestas y contrapropuestas deben ser serias, razonables y coherentes, proveyendo la información necesaria para un claro entendimiento por la parte contraria. Derivado del principio general de buena fe, surge un deber de cooperación que implica que las partes deben conducir las negociaciones con flexibilidad y tomando en consideración no solo sus intereses, sino los de su contraparte, evitando por tanto las dilaciones injustificadas como el término abusivo o intempestivo de las negociaciones. Así, en materia arbitral se ha señalado que el principio de conducir las negociaciones de buena fe supone "el mantenimiento de la negociaciones por un período adecuado a las circunstancias, la consideración de los intereses de la contraparte y la búsqueda persistente de un acuerdo razonable" 59 .

\section{LA SUERTE DEL CONTRATO DURANTE EL PERÍODO DE RENEGOCIACIÓN}

La renegociación del contrato implica necesariamente un período de incertidumbre en relación con los efectos originales del contrato. La determinación de los efectos jurídicos para las partes durante tal período es de extrema relevancia, especialmente si las renegociaciones se extienden por un espacio prolongado de tiempo.

En cuanto a la extensión del período de renegociación del contrato, tanto los Principios Unidroit como los PECL se refieren a un "período razonable" para efectuar las negociaciones y llegar a un acuerdo. La fórmula parece adecuada si la vinculamos a la naturaleza y complejidad del contrato en el caso particular, así como a otras circunstancias externas verificables objetivamente, como por ejemplo la lejanía física de los contratantes o su estructura jurídica en cuanto a los procesos de toma de decisiones vinculantes.

Por otra parte, en relación a la exigibilidad de las prestaciones durante el período de renegociaciones, como principio general puede establecerse que el contrato se mantiene vigente a menos que las partes acuerden expresamente lo contrario. Solo en circunstancias muy excepcionales puede permitirse a la parte afectada suspender el cumplimiento de sus obligaciones. Así lo establecen expresamente los Principios Unidroit en su artículo 6.2.3. Al contrario, tal como se indicó, el proyecto de la Chancellerie de reforma del Code Civil establece la regla contraria al proveer que el contratante que requiere la

\footnotetext{
58 Véase artículo 6.2.3(1) de los Principios Unidroit.

${ }^{59}$ Kuwait v. American Independent Oil Company (en adelante, el caso Aminoil). El tribunal arbitral citó en su fallo la decisión de la Corte Internacional de Justicia en los casos North Sea Continental Shelf: “... (las partes) están sujetas a la obligación de comportarse de manera que las negociaciones sean serias, lo que no ocurre cuando cualquiera de ellas insiste en su propio planteamiento sin contemplar modificación alguna en él". (8I.C.J Reports, 1969, 4 at 47, 48).
} 
modificación del contrato debe cumplir son sus obligaciones originalmente pactadas durante el período de renegociaciones (art. 136 inc. 2).

El autor estima que una alternativa es establecer un requisito de "cumplimiento mínimo” del contrato por la parte que solicita la renegociación. Así, considerando que la intención del contratante que requiere la renegociación es preservar la relación contractual y no terminarla, y que la ejecución del contrato es posible aun cuando mucho más onerosa, la propuesta de modificación debería incluir también una propuesta de "cumplimiento mínimo" del contrato durante el período de renegociaciones, que sea razonable para los intereses de ambas partes. Dicha propuesta puede incluso coincidir con la propuesta general de modificación, sin perjuicio que esta sea en definitiva rechazada o alterada durante las negociaciones.

En los casos en que las partes no logren acuerdo en esta materia o que la renegociación sea ordenada por el tribunal, este deberá establecer necesariamente las condiciones de cumplimiento o suspensión del contrato durante las negociaciones, incluyendo también un término máximo para que estas se lleven a efecto.

\section{3) El DEBER DE ACEPTAR UNA PROPUESTA JUSTA Y RAZONABLE}

Quizás uno de los aspectos más interesantes en cuanto al contenido del deber de renegociar, es el relativo al eventual deber que tendrían las partes de aceptar la propuesta formulada por la otra, cuando dicha propuesta es justa, razonable y se adecua a los intereses de ambas partes.

Al respecto, la jurisprudencia de la Cour de Cassation ha establecido que las cláusulas de renegociación no imponen en caso alguno la obligación de aceptar la propuesta hecha por la contraparte, sino tan solo el deber de renegociar los términos del contrato bajo los principios de la buena fe y la lealtad comercial ${ }^{60}$. En el mismo sentido, fallos arbitrales han establecido que la incapacidad de las partes de llegar a un acuerdo tras un período de renegociación no constituye un caso de incumplimiento contractual, ya que "el deber de renegociar no incluye la obligación de llegar a acuerdo" y que "(la parte requerida) no puede ser legalmente obligada a aceptar el acuerdo, por muy razonable que este pueda ser" 61 . Bajo esta perspectiva, la única obligación para las partes es entrar efectivamente en negociaciones y comportarse en ellas de buena fe, no siendo la modificación del contrato una obligación sino tan solo una mera expectativa, inexigible jurídicamente. De esta manera, la naturaleza jurídica del deber de renegociar sería la de una obligación de medios, que se cumple siempre que las partes efectivamente negocian de buena fe la adaptación del contrato a las nuevas circunstancias, no siendo relevante si las partes llegan en definitiva a un acuerdo ${ }^{62}$.

Sin embargo, parte de la doctrina francesa ha sostenido que en caso que exista una cláusula en el contrato que establezca la renegociación del mismo en determinados supuestos, la intención de las partes al incorporar tal cláusula (otorgar estabilidad a la

60 Cass. com., 3 de octubre 2006.

${ }^{61}$ Caso Aminoil y Wintershall A.G. $v$ Gov't of Qatar.

62 Ghestin et al. (2001) p. 312. 
relación y preservar el contrato en caso de circunstancias sobrevinientes) y el principio de buena fe que debe gobernar el contrato, hacen surgir el deber de aceptar una propuesta de modificación razonable y justa ${ }^{63}$. En el mismo sentido, también exigiendo la existencia de cláusula expresa, la doctrina alemana ha señalado que tal obligación surge en aquellos casos en que el objeto y los criterios de ajuste hayan sido fijados en el contrato $^{64}$.

Asimismo, la doctrina norteamericana partidaria de la teoría relacional del contrato también ha sostenido la existencia de la obligación de aceptar una propuesta de modificación razonable y efectuada de buena fe. El rechazo de tal propuesta por la parte aventajada implica la trasgresión de las exigencias de la solidaridad contractual, la preservación de la relación y la armonización de los conflictos, presentes en los contratos con características relacionales; y al contrario, demuestra la intención de dicha parte de aprovechar ventajas que van más allá de las originalmente negociadas, y que por tanto no pueden justificarse en el acuerdo inicial. En este sentido, se ha señalado que si "la parte aventajada debería haber aceptado la modificación equitativa (del contrato) con el objeto de redistribuir ganancias y pérdidas no negociadas y preservar la relación, entonces la parte perjudicada tiene derecho a un remedio consistente en aquello que debería haberse aceptado" 65 .

Si en definitiva se acepta la existencia de la obligación de aceptar una propuesta de modificación justa y razonable, la cuestión que surge de inmediato es determinar cuándo una propuesta reúne tales condiciones. Al efecto se ha sostenido que el análisis debe ser efectuado en dos sentidos ${ }^{66}$.

Primero, debe descartarse un eventual oportunismo del contratante afectado, de manera que la propuesta de modificación debe estar basada en circunstancias externas y verificables que permitan desechar la sola consecución de objetivos estratégicos de su parte o el aprovechamiento mediante la renegociación de oportunidades que no tomó en cuenta al momento de contratar. Un parámetro en este sentido puede ser el hecho que las circunstancias imprevisibles afecten a toda una clase de contratantes situados en una misma posición (p. ej. los proveedores de un determinado bien) y no solo al contratante en particular. Otro parámetro a analizar es el rol de la inflación como evento sobreviniente. Así, el peligro de oportunismo por parte del vendedor es mayor cuando la circunstancia modificatoria del equilibrio contractual es una inflación que aumenta de manera importante el precio de mercado de los bienes objeto del contrato; y por otra parte, es menor si la inflación ha afectado los costos de producción de tales bienes. Lo mismo puede decirse si la propuesta implica cambios en la cantidad de bienes objeto del contrato más que en el precio acordado.

Segundo, la propuesta debe ser equitativa en relación a la naturaleza de las circunstancias sobrevinientes y el efecto que estas han tenido sobre la prestación de la parte

\footnotetext{
63 OpPetit (1974) p. 807.

64 Berger (2003), p. 1367.

65 SPEIDEL (1981-1982) p. 416.

${ }^{66}$ Ibid. pp. 408-410.
} 
afectada. Así, la parte perjudicada tiene la carga de indicar claramente en su propuesta los hechos constitutivos de la onerosidad sobreviniente y la manera en la cual tales circunstancias han influido en la distribución de riesgos y costos asumidos expresa o tácitamente por las partes al momento de celebrar el contrato, proveyendo a tal efecto toda la información necesaria para un adecuado entendimiento y evaluación de la propuesta por la contraparte. Como punto de partida para la determinación de la equidad de la propuesta, puede decirse que esta debe comprender una distribución "compensatoria" de los nuevos costos generados por los eventos sobrevinientes, que de acuerdo con la distribución de riesgos del contrato no deban ser asumidos por la parte afectada. En todo caso, no puede considerarse compensatoria (y por tanto, tampoco razonable y equitativa) la propuesta que pretenda trasladar el $100 \%$ de los nuevos costos a la parte aventajada. Al efecto, el contratante perjudicado por las circunstancias sobrevinientes no puede reclamar la restauración completa y absoluta del equilibrio contractual tal y como existía al momento de la celebración del acuerdo, sino tan solo en aquella parte que, según la distribución de riesgos del contrato, ha transformado su prestación en excesivamente onerosa. Si la totalidad de las consecuencias de la onerosidad sobreviniente fuese trasladada a la parte aventajada (que asume por tanto íntegramente los nuevos costos) el resultado sería tan injusto como el que se pretende evitar. En definitiva, parte de las pérdidas deben ser asumidas por la parte afectada ${ }^{67}$.

En caso de aceptarse la existencia de este deber, el rechazo de una propuesta justa y razonable implicaría el incumplimiento del contrato, lo que habilitaría entonces al proponente para solicitar indemnización de perjuicios y la resolución del contrato.

Sin embargo, el autor estima dudosa la existencia del referido deber. Al efecto, creemos que lo esencial es analizar la buena o mala fe de la parte a la cual se dirige la propuesta, de manera de determinar en base a dicha conducta las consecuencias del fracaso de las negociaciones, las cuales, como se expondrá más adelante, pueden incluir la indemnización de perjuicios y la resolución del contrato. Además, si la parte que ha propuesto la adaptación del contrato quiere perseverar en él, el problema se soluciona concediendo al juez la facultad de revisar el contrato, pudiendo considerar como alternativa válida para su adaptación la propuesta rechazada.

\section{LA SITUACIÓN DESPUÉS DEL TÉRMINO DE LAS NEGOCIACIONES. CONSECUENCIAS DE SU ÉXITO O FRACASO}

\section{1) El ÉXITO DE LAS NEGOCIACIONES}

El hecho que las partes logren acuerdo en la renegociación del contrato, implica necesariamente que la prestación de al menos una de ellas será alterada. Por ello, resulta interesante examinar la naturaleza de esta modificación, de manera de establecer si se ha

67 BRUNNER (2008) p. 499. En el mismo sentido, véase los PECL, comentario D artículo 6:111. En contra, SPEIDEL (1981-1982) p. 410, quien señala que "un standard constante (para una propuesta razonable y equitativa) podría ser que a la parte afectada se le paguen los costos adicionales de producción más el porcentaje de ganancia que hubiese obtenido según el contrato original”. 
producido una novación, habiéndose extinguido por tanto la obligación primitiva, o si estamos en presencia de la misma obligación pero modificada. Lo anterior tiene evidente importancia, por ejemplo, en relación con las garantías constituidas por el deudor o terceros y en materia de prescripción.

Como regla general, puede señalarse que no existirá novación debido a que no se cumplirá con el requisito que exige una diferencia sustancial entre la primitiva y la nueva obligación. Así, si pensamos en contratos de compraventa o suministro, en general la modificación de la obligación del vendedor o suministrador será la reducción de la cantidad a entregar o la ampliación del plazo para tal entrega, ambos casos expresamente señalados en el Código como no constitutivos de novación (arts. 1646 y 1649, respectivamente). Por otra parte, si la obligación que se modifica es aquella de la parte que debe pagar el precio, los cambios en el mismo o en sus accesorios (como el sistema de reajustabilidad) tampoco implican novación ${ }^{68}$. En suma, por regla general, ninguno de los elementos esenciales de la obligación sufrirán cambios que puedan considerarse como constitutivos de novación, o bien, la modificación recaerá sobre elementos accidentales de la prestación. No existirá por tanto novación (arts. 1649 y 1650 del Código), subsistiendo la obligación original, sin perjuicio que deberán protegerse adecuadamente los derechos de terceros que no hayan concurrido a la modificación.

En Francia se ha llegado a la misma conclusión por la vía de argumentar la falta de animus novandi de las partes. Al efecto, se señala que la intención de las partes al renegociar el contrato no es ponerle término, sino mantener la relación contractual original pero adaptándola a las nuevas circunstancias. Se agrega que solo en casos excepcionales de variación sustancial de la obligación primitiva o en casos de resciliación expresa, puede entenderse que la obligación original se ha extinguido siendo sustituida por una nueva ${ }^{69}$.

\section{2) LOS EFECTOS DEL FRACASO DE LAS NEGOCIACIONES}

\section{1) Indemnización de perjuicios y extinción del contrato}

En caso que las partes hayan fracasado en su intento de lograr un acuerdo modificatorio del contrato, los efectos de tal fracaso dependerán básicamente de la buena o mala fe con que las partes hayan conducido las negociaciones.

Así, aun cuando las partes hayan actuado de buena fe durante el proceso de renegociación, este puede fracasar debido a legítimas discrepancias que les impidan llegar a un acuerdo sobre la adaptación del contrato a las nuevas circunstancias. En este caso, debido a que no hay incumplimiento de algún deber de conducta u obligación, los efectos del fracaso de las negociaciones se reducen a la extinción del contrato o a su adaptación por un tercero imparcial (en general el juez o un árbitro) ${ }^{70}$.

\footnotetext{
${ }^{68}$ Así, se ha fallado que la disminución de la deuda no constituye novación (RDJ, T. 21, sec. 1a p. 461), como tampoco lo es el aumento de la tasa de interés (RDJ, T. 2, sec. 1a, p. 217). Fallos citados por ABELIUK (2001) pp. 991-995.

${ }^{69}$ GHeSTIN et al. (2001) p. 314.

70 Se parte del supuesto que las condiciones para la aplicación de la excesiva onerosidad sobreviniente se cumplen, por lo que el juez no optará por dejar vigente el contrato en sus términos originales.
} 
Al efecto, se estima que el término del contrato no es la solución más adecuada para los intereses de las partes, en particular si ambas desean perseverar en el contrato (pero no les ha sido posible llegar a un acuerdo relativo a los términos para ello) o en los casos que se trate de bienes disponibles solo en mercados restringidos (lo que puede implicar, por ejemplo, la imposibilidad para el adquirente de obtener bienes o servicios equivalentes a los originalmente pactados). Además, la extinción del contrato puede perjudicar intereses de terceros no representados en la disputa como también intereses públicos en general (como en el caso que el objeto del contrato sea la provisión de algún servicio público). En virtud de lo anterior, la extinción del contrato debe considerarse como la alternativa extrema para estos casos, solo aplicable cuando la preservación del contrato por medio de su ajuste a las nuevas circunstancias no sea posible o haya perdido su propósito. Adicionalmente, con el objeto de mitigar los efectos adversos de la extinción del contrato respecto de las partes y terceros, el juez debe estar provisto de amplias facultades para determinar los términos de la misma en relación a su fecha, retroactividad, prestaciones pendientes o parcialmente cumplidas y perjuicios, entre otros. Así lo establecen las normas aplicables a la materia de los Principios Unidroit, los PECL y el DCFR, como también el Proyecto de la Chancellerie.

Por otra parte, si ha sido la actuación de mala fe de una de las partes la que ha impedido el acuerdo, o si simplemente una de las partes se ha negado injustificadamente a renegociar el contrato, la otra tiene derecho a demandar los perjuicios que de tal actuación se deriven, además de la resolución del contrato ${ }^{71}$. Así lo estipulan expresamente los PECL. Además, en derecho chileno, la negativa injustificada a renegociar puede configurarse como un caso de incumplimiento del contrato (en relación con lo establecido en el artículo 1546 del Código Civil), por lo cual el deudor afectado podrá interponer la excepción de contrato no cumplido (artículo 1552 del Código) ${ }^{72}$.

\section{2) La revisión y adaptación del contrato por el juez}

La posibilidad que el juez pueda modificar el contrato para adaptarlo a las nuevas circunstancias es sin duda la más controversial de los posibles efectos del fracaso de las negociaciones ${ }^{73}$. En este sentido, codificaciones modernas como la holandesa y la alemana contemplan expresamente la modificación del contrato por el juez como uno de los efectos de la excesiva onerosidad ${ }^{74}$. Por otra parte, la revisión del contrato es rechazada tradicionalmente en los sistemas de Common law, especialmente en el derecho inglés ${ }^{75}$.

\footnotetext{
${ }^{71}$ La ejecución forzada del deber de renegociar no parece una alternativa realista, ya que al tratarse de una obligación de hacer implica la realización de una conducta personal que no es posible de obtener coercitivamente.

72 En el mismo sentido, DÖRR (1985) p. 269.

73 En este artículo, la revisión judicial del acuerdo solo será analizada en su relación con el deber de renegociación y como consecuencia eventual de su fracaso, y no en cuanto a efecto autónomo de la excesiva onerosidad sobreviniente, lo cual requiere un estudio mucho más extenso que excede el objeto de este trabajo.

${ }^{74}$ Artículo 6:258 del $B W$ holandés y $\$ 313$ del $B G B$ alemán.

75 BEALE et al. (2001) p. 886.
} 
El derecho francés también ha mantenido una actitud conservadora en esta materia, rechazando la revisión del contrato por los tribunales en los casos de imprévision ${ }^{76}$. Tal como se señaló, los argumentos para este rechazo pueden aún encontrarse en la sentencia de la Cour de Cassation recaída en el caso del Canal de Craponne y en la doctrina tradicional francesa. En este sentido, se estima que solo las partes están las legitimadas para alterar las convenciones que libremente han concluido, ya que en vista de los principios de autonomía de la voluntad y libertad contractual, son las únicas calificadas para determinar los términos del contrato que mejor convengan a sus intereses. Siguiendo esta tradición, el Proyecto Catala de reforma al Code Civil no contempla la posibilidad de revisión del contrato por el juez para el caso que las partes no lleguen a acuerdo en la renegociación del contrato, sino solo da derecho a cada parte a terminar el contrato sin derecho al reembolso de gastos ni perjuicios. Por otra parte, el proyecto de reforma presentado por la Chancellerie también es conservador al respecto, ya que permite al juez modificar el contrato, pero solo en el caso excepcional que ambas partes así lo acuerden, lo que en definitiva hace que la norma carezca de relevancia práctica. En caso contrario, el juez puede poner término al contrato en los términos que estime más adecuados para el caso particular.

No obstante lo señalado respecto de la jurisprudencia de la Cour de Cassation, existen, sin embargo, sentencias de Cortes de Apelaciones francesas que han admitido la posibilidad que el juez pueda revisar el contrato en caso que las negociaciones entre las partes no tuviesen éxito. Así, la Corte de Apelaciones de París en Electricité de France c/ Shell Française estableció que habiéndose demostrado la común intención de los contratantes de preservar el contrato y adaptarlo a las nuevas circunstancias (aun cuando no les había sido posible llegar a acuerdo al respecto), y considerando el interés público envuelto en su ejecución, las partes debían retomar las negociaciones con la asistencia de un tercero imparcial (un observateur) designado por la Corte para intentar resolver sus diferencias. Pero además la Corte agregó que en caso que estas nuevas negociaciones no fueran exitosas, se reservaba en tal caso la facultad de revisar y adaptar el contrato. En el mismo sentido, la Corte de Apelaciones de Nancy en SAS Novacarb c/ SNC Socoma sostuvo que las partes debían entrar en negociaciones con el objeto de adaptar el contrato en razón que el equilibrio económico de las contraprestaciones había sido gravemente alterado por circunstancias imprevisibles al tiempo de su ejecución. Pero la Corte también dispuso que si dichas negociaciones fracasaban, el tribunal tenía la facultad de revisar el contrato por medio del examen de la intención común de las partes y la interpretación de las cláusulas esenciales del contrato, sin perjuicio de ordenar la indemnización de perjuicios si la ruptura de las negociaciones se debía a la mala fe de alguna de ellas.

En materia de contratación internacional, los tribunales arbitrales han establecido que la posibilidad de revisar el contrato celebrado por las partes debe derivarse claramente de los términos de la cláusula de renegociación y del acuerdo de las partes que somete la cuestión a arbitraje. Así, en el caso Aminoil, el tribunal arbitral estableció que

${ }^{76}$ MAZEAUd (2007) p. 770. 
"en general, un tribunal no puede sustituir a las partes con el objeto de mejorar o modificar el contrato, a menos que tal derecho le haya sido conferido por la ley o por el consentimiento expreso de los contratantes". Sin perjuicio de ello, también existen fallos que han determinado que el tribunal arbitral tiene la facultad de modificar un contrato en equidad bajo las normas de la excesiva onerosidad sobreviniente, pero siempre como una excepción calificada del principio pacta sunt servanda ${ }^{77}$.

Como ya se ha expresado, modernos cuerpos normativos internacionales regulan la materia en sentido opuesto, es decir, contemplan expresamente la facultad del juez de revisar y adaptar el contrato en estos casos. Así, como se señaló anteriormente, los Principios Unidroit, los PECL y el DCFR establecen que en caso de fracasar las negociaciones entre las partes, cualquiera de ellas puede recurrir al juez para que este modifique el contrato con el objeto de restaurar el equilibrio entre las contraprestaciones y distribuir de manera justa y equitativa las ganancias y pérdidas generadas por el cambio de circunstancias, entregando al juez amplias facultades tanto para la decretar tanto la modificación del contrato como su extinción, según sea más adecuado para las circunstancias del caso particular.

Parte de la doctrina norteamericana también se ha mostrado favorable a la revisión del contrato por el juez una vez que las renegociaciones entre las partes han fracasa$\mathrm{do}^{78}$. Estos autores postulan que en el caso de contratos de largo plazo, soluciones extremas o de "todo o nada" en virtud de las cuales los efectos de la excesiva onerosidad sobreviniente se reducen al cumplimiento forzado del contrato en caso de ser rechazada la pretensión de la parte afectada o su extinción en caso que tal pretensión sea acogida, no son las más adecuadas en consideración de la complejidad e importancia de los intereses envueltos en el contrato, que se relacionan no solo con las partes sino también con intereses públicos o de terceros, muchas veces no representados en el litigio. De esta manera, se sostiene que en la mayoría de los casos la preservación del contrato debe ser preferida a su terminación, aun cuando la intervención del juez se plantea siempre como el último recurso ${ }^{79}$. Sin embargo, esta doctrina en general condiciona la intervención del juez en el contrato a la mala fe de alguna de las partes en el proceso de negociación, ya sea que tal parte se haya negado injustificadamente a renegociar o bien que las renegociaciones hayan fracasado debido a dicha mala $\mathrm{fe}^{80}$. Así, la negativa injustificada de la parte aventajada a aceptar una propuesta equitativa y efectuada de acuerdo a la buena fe

77 ICC Award No. 7365/FMS (May. 5, 1997) y No. 9479 (Feb. 1999); citados por BoNNEL, supra note 64 at 338 .

${ }^{78} \mathrm{La}$ modificación de los términos de un contrato no es ajena al Common law de los Estados Unidos. Así, el remedio denominado reformation puede ser concedido bajo principios de equidad cuando la letra del contrato no refleja el verdadero acuerdo celebrado por las partes, por ejemplo, un error de redacción o la omisión de una cláusula efectivamente acordada, como en Nichols v. Shelard National Bank y en Japhe v. A-T-O Inc. Véase SPEIDEL (1981-1982) p. 379.

${ }^{79}$ HALPERN (1986-1987) p. 1173.

${ }^{80}$ Hillman (1987) pp.18 y 19, y Speidel (1981-1982) p. 405. Debe precisarse que Speidel restringe la posibilidad de adaptación judicial a contraltos de larga duración, señalando como especiales características de ellos su duración prolongada en el tiempo, la creación de relaciones complejas y especializadas entre las partes y el involucramiento de intereses públicos y de terceras partes en la ejecución del contrato. 
por la contraparte daría lugar entonces al derecho a solicitar que tal propuesta sea impuesta por el juez. La base para esta argumentación estaría en los Comentarios 6 y 7 del artículo 2-615 del UCC, que establecen la posibilidad de ajustar el contrato según las disposiciones del mismo artículo y en particular de la buena fe, en aquellos casos en que las alternativas extremas de excusa o no excusa para el deudor no sean adecuadas para evitar situaciones de injusticia. Como puede apreciarse, esta postura implica necesariamente que el juez debe analizar la conducta de las partes y los motivos de la negativa a negociar o del rechazo de la propuesta, no pudiendo intervenir por el solo hecho de haber fracasado las partes en sus intentos de llegar a un acuerdo.

En este sentido, la jurisprudencia norteamericana ha adoptado en algunos casos una solución que podríamos llamar intermedia en relación a ajustes en el precio del contrato, condicionando el cumplimiento forzado del contrato a la aceptación por parte del demandante de una modificación equitativa del precio pactado, a propuesta del demandado, ante un cambio sobreviniente de circunstancias ${ }^{81}$. El segundo Restatement de contratos también reconoce expresamente esta alternativa ${ }^{82}$. En el mismo sentido, se ha argumentado que la sección 2-716(2) del UCC también facultaría al juez para revisar el precio del contrato condicionando la resolución que ordena el cumplimiento forzado a la modificación equitativa del precio ${ }^{83}$.

Por último, es necesario destacar que existe un único y aislado caso en la jurisprudencia norteamericana, Aluminium Co. of America (Alcoa) v. Essex Group, Inc., en adelante el caso Alcoa, en que se ha decretado la modificación del contrato en virtud de excesiva onerosidad sobreviniente, constituida en este caso por el abrupto y drástico aumento de los costos de producción de Alcoa debido a la crisis energética del año 1973. En primera instancia, la Corte Federal de Distrito falló a favor de Alcoa, sosteniendo que había existido error (mistake) en la elección del índice de reajuste y además commercial impracticability, esto es, excesiva onerosidad sobreviniente, decretando la modificación del contrato por medio de la sustitución del índice de reajustabilidad pactado por uno nuevo establecido por el tribunal, con el objeto de redistribuir entre las partes las riesgos y pérdidas generados por las nuevas circunstancias y de esta manera reducir los costos de Alcoa a cantidades tolerables por la empresa. En su decisión, el juez destacó como requisito esencial para su intervención en el contrato, la necesidad que las negociaciones previas entre las partes para modificarlo hubiesen fracasado, de manera que la revisión judicial del acuerdo tuviese siempre el carácter de "último recurso" para los contratantes ${ }^{84}$.

81 Willard v. Tayloe, City of LaFollette v. LaFollette Water, Light \& tel. Co.

82 Restatement (2nd) of Contracts, $\$ 358$.

${ }^{83}$ SPEIDEL (1981-1982) p. 417. La sección 2-716(2) provee que "El decreto de ejecución forzada puede incluir términos y condiciones relativos al pago del precio, daños u otra excusa que la Corte considere justa". Sin embargo, en Iowa Electric Light \& Power Co. v. Atlas Corp., la Corte determinó que no tenía facultades para condicionar la ejecución forzada del contrato en base a esta norma.

${ }^{84}$ No obstante, elevado el caso en apelación, la Corte instó a las partes a llegar a un acuerdo, el que finalmente se produjo en virtud de la incertidumbre del resultado de la causa en segunda instancia. De esta manera, la decisión del juez de primera instancia, relativa a la modificación del contrato, nunca se llevó a efecto. 
Sin perjuicio del carácter innovador y original de la sentencia del caso Alcoa y de la extensa y controvertida bibliografía que generó, la decisión no ha sido seguida como precedente en casos posteriores y solo dos jueces (uno de la Corte Suprema de West Virginia y otro de una Corte Federal en New Jersey) han citado el fallo en los fundamentos de sus decisiones ${ }^{85}$. Por estas razones, se ha dicho que el verdadero valor de este caso fue poner de manifiesto el rol de las decisiones judiciales como incentivo para que las partes resuelvan sus diferencias mediante acuerdo ${ }^{86}$. En este sentido, otras decisiones judiciales han también destacado la necesidad que el juez adopte una conducta activa durante el litigio, incentivando a las partes a negociar para la resolución privada de sus disputas ${ }^{87}$.

\section{CONCLUSIONES}

En base a lo expuesto, el autor estima que puede plantearse en Chile la existencia de un deber de renegociación para las partes en casos de excesiva onerosidad sobreviniente. El fundamento normativo esencial está dado por el artículo 1546 del Código Civil, que establece el deber de buena fe en la ejecución de los contratos. El principio pacta sunt servanda, establecido en términos explícitos y categóricos por el artículo 1545, debe ser necesariamente calificado en situaciones extraordinarias a través de la aplicación del principio de buena fe. En este sentido, en el contexto internacional y comparado, se ha otorgado como función a la buena fe la mitigación del rigor de la ley, con el propósito de equilibrar el principio de seguridad jurídica con la justicia para el caso particular, de manera de obtener soluciones equitativas en casos excepcionales, que de otra manera resultarían en una manifiesta injusticia para una de las partes ${ }^{88}$. Así, en caso de producirse un cambio sobreviniente e imprevisible de circunstancias, que desvirtúa de tal manera la relación contractual que las partes tuvieron en vista al momento de contratar y que perturba de manera sustancial el equilibrio entre las prestaciones, alterando gravemente la legítima distribución de ganancias y pérdidas que las partes podían esperar; es justo limitar la estricta aplicación del principio pacta sunt servanda y buscar el restablecimiento del equilibrio contractual hasta el límite del riesgo que razonablemente hubieren asumido los contratantes. Al efecto, sin duda que los más capacitados y legitimados para llevar a efecto dicha tarea son las propias partes, debiendo entonces renegociar de buena fe los términos del contrato con el objeto de adaptarlo a las nuevas circunstancias. Solo en caso de fracaso en las negociaciones, podrá el juez intervenir en el contrato a través de su adecuación a las nuevas circunstancias o su terminación, debiendo otorgársele amplias facultades para dichos efectos.

\footnotetext{
85 McGinnis v. Cayton y Unihealth v. U.S. Healthcare Inc. Véase WHITE y Peters (2001-2002) p. 1973, destacando que si bien ambas opiniones se refieren al caso Alcoa, los hechos y el resultado final de los casos son diversos de aquel.

${ }^{86}$ MaCaUlay (1985) pp. 475 y 476.

87 In re Westinghouse Elec. Corp. Uranium Contracts Litig.

88 Vogenauer y Kleinheisterkampf (2009), p. 179. En este sentido, el $B W$ holandés establece expresamente en su art. 6:248 que una norma obligatoria para las partes no se aplicará, en el caso particular, si ello es inaceptable de acuerdo a criterios de razonabilidad o equidad.
} 
En definitiva, el deber de renegociación es una alternativa ecuánime para ambas partes, ya que contribuye a eliminar los efectos negativos de la onerosidad sobreviniente, esto es, las pérdidas y ganancias inmerecidas de una parte a costa de la otra, evitando en el hecho la extinción del contrato o su incumplimiento, de manera que ambas partes puedan continuar beneficiándose con su existencia, e idealmente, permite reflejar lo que los contratantes hubiesen pactado en caso de haber previsto la ocurrencia de las circunstancias sobrevinientes que afectaron el contrato.

\section{BIBLIOGRAFÍA CITADA}

Abeliuk, René (2001): Las obligaciones, t. 2 (Santiago, Ed. Jurídica de Chile) 617 pp.

Beale, H.G., Bishop, W.D. and Furmston, M.P. (2001), Contract, Cases and Materials, $4^{\text {th }}$ edition (London Butterworths) pp. 1256.

BERGER, Klaus (2003): Renegotiation and Adaptation of International Contracts: The Role of Contract Drafters and Arbitrators, 36 Vand, J. Transnat'l L., pp. 1347 1380.

Bonnel, Michael (2006): The Unidroit Principles in Practice, 2 $2^{\mathrm{a}}$ edición (Ardsley, Transnational Publishers) 1156 pp.

Brunner, Christoph (2008): Force Majeure and Hardship under general contract principles (La Haya, Kluwer Law International) 624 pp.

BusCH, Danny et al. (eds.) (2002): The Principles of European Contract Law and Dutch Law, A Commentary (Nijmegen and London, Ars Aequi Libri and Kluwer Law International), $471 \mathrm{pp}$.

Capitant, Henri; Terré, François y LequetTe, Ives (2000): Les grands arrêts de la jurisprudence civile, T. 2: Obligations, Contrats spéciaux, Sûretés, $11^{\mathrm{a}}$ edición (París, Dalloz) 675 pp.

Domínguez, Ramón; PizArro, Carlos; TAPIA, Mauricio; y RíOS, Sebastián (2008): La révision du contract, Rapport Chilien, en Journées Brésiliennes, Association Henri Capitant (Paris, Société de Légis lation Comparée), pp. 513-528.

Dörr, Juan Carlos (1985): "Notas acerca de la teoría de la imprevisión”, Revista Chilena de Derecho, V. 12, pp. 253-270.

EISENBERG, Melvin A. (1999-2000): Why There Is No Law of Relational Contracts, 94 Nw. U. L. Rev., pp. 805-821.

FARNSWORTH, E. Allan (1963): Good Faith Performance and Commercial Reasonableness Under the Uniform Commercial Code, 30 U. Chi. L. Rev., pp. 666-679.

Fauvarque-Cosson, Bénédicte y Mazeaud, Denis (2008): Principes Contractuels Communs, Paris, Société de Législation Comparée, 853 pp.

Fueyo, Fernando (1990): "La ejecución de buena fe, del art. 1546 del Código Civil, es uno de los requisitos legales del pago y como tal se proyecta como fundamento de la indexación y desindexación", en FUEYO, Fernando, Instituciones de Derecho Civil Moderno (Santiago, Ed. Jurídica de Chile), pp. 179-237.

Ghestin, Jacques; Jamin, Christophe; Billiau, Marc (2001): Traité de Droit Civil. Les Obligations. Les Effets du Contrat (Paris, LGDJ) 1340 pp. 
Goetz, Charles J. y Scott, Robert E. (1981): "Principles of Relational Contracts", 67 Va. L. Rev., pp. 1089-1150.

HALPERN, Sheldom W. (1986-1987): Application of the Doctrine of Commercial Impracticability: Searching for the 'Wisdom of Solomon', 135 U. Pa. L. Rev., pp. 11231178.

Hillman, Robert (1987) Court Adjustments of Long-Term Contracts: An Analysis Under Modern Contract Law, 1987 Duke L.J., pp. 1-33

Hondius, Ewoud (2007): "Towards a New General Part of the French Law of Obligations: Two Faces of the Catala Project", en Andenas, Mads; Diaz Alabart, Silvia; Markensis, Basil; Micklitz, Hans and Pasquini, Nello (edits.), Liber Amicorum Guido Alpa, Private Law Beyond the National Systems (Londres, British Institute of International and Comparative Law), 1112 pp.

HorN, Norbert (1985): "Changes in Circumstances and the Revision of Contracts in Some European Laws and in International Law”, en HoRN, Norbert (edit.), Adaptation and Renegotiation of Contracts in International Trade and Finance (Deventer, Kluwer Law International), $421 \mathrm{pp}$.

KARAmpatzos, Antonis (2005): "Supervening Hardship and Subdivision of the General Frustration Rule: A Comparative Analysis with Reference to Anglo - American, German, French and Greek Law", en European Review of Private Law, 2-2005, pp. 105134.

Lando, Ole y Beale, Hugh (2000): Principles of European Contract Law, Parts I and II, (La Haya, Kluwer Law International) 561 pp.

LiTVinOfF, Saul (1985-1986): "Force Majeure, Failure of Cause and the Théorie de L'imprévision: Louisiana Law and Beyond”, en 46 La. L. Rev. pp. 1-63.

LOREnZ, Werner (1995): “Contract Modifications and Change of Circumstances", en Beatson, Jack y Friedmann, Daniel (edit.), Good Faith and fault in Contract Law (Oxford, Clarendon Press), 531 pp.

MACARIO, Francesco (1996): Adeguamento e Rinegoziazione nei Contratti a Lungo Termine (Nápoles, Jovene Editore), pp. 442.

Macaulay, Stewart (1985): "An Empirical View of Contract", 1985 Wis. L. Rev., pp. 465-482.

MACKENDRICK, Ewan (1991): "Frustration and Force Majeure - Their Relationship and Comparative Assessment", en MACKEndrick, Ewan (edit.), Force Majeure and Frustration of Contract, (London, Lloyd's of London Press Ltd.), 235 pp.

MaCneIL, Ian (1980): The New Social Contract: An Inquiry Into Modern Contractual Relations, (New Haven, Yale U.P.), 164 pp.

MaZeaud, Henry; MAZEAUd, Léon; MaZEAud Jean y CHABAS François (1996): Leçons de Droit Civil, T.II, Premier Volume, Obligations, Théorie Generale (Paris, Montrechstein) $1353 \mathrm{pp}$.

MAZEAUD, Denis (2004): Du nouveau sur lóbligation de renégocier, en Recueil Dalloz, 2004, n² 25, pp. 1754-1758.

MAZEAUD, Denis (2007): Renégocier ne rime pas avec réviser!, en en Recueil Dalloz, 2007, nº 11, pp. 765-770. 
Momberg, Rodrigo (2008) "Análisis crítico desde el derecho alemán y nacional de la sentencia de la Corte de Apelaciones de Santiago que acoge la teoría de la imprevisión”, en GuZmán Brito, A. (ed.), Estudios de Derecho Civil III (Santiago, Legal Publishing) pp. 637-658.

Oppetit, Bruno (1974): "L'adaptation des contrats internationaux aux changements de circonstances: la clause de "hardship"” en 1974 J. de Droit Int., pp. 794-814.

PeÑAilillo, Daniel (2000a): "La revisión judicial de obligaciones y contratos en la reforma del Código Civil (la lesión y la imprevisión)", en Revista de Derecho, Universidad de Concepción, N²08, pp. 209-237.

Peñailillo, Daniel (2000b): Estudios sobre Reformas al Código Civil y al Código de Comercio, Fundación Fernando Fueyo Laneri (Santiago, Ed. Jurídica de Chile), p. 356.

PeñAilillo, Daniel (2003): Obligaciones. Teoría General y Clasificaciones (Santiago, Ed. Jurídica de Chile), 502 pp.

SENDEN, L., "Soft Law, Self-Regulation and Co-Regulation in European Law: Where do they meet?", en Electronic Journal of Comparative Law, vol. 9.1 (January 2005), disponible en http://www.ejcl.org/91/art91-3.PDF

SOMMER, Robert (1974-1975): "Commercial Impracticability - An Overview", en 13 Duq. L. Rev., pp. 521-550.

SPEIDEL, Richard E. (1981-1982): "Court-Imposed Price Adjustments Under LongTerm Supply Contracts”, 76 Nw. U. L. Rev., pp. 369-422.

Trakman, L (1984-1985): Winner Take Some: Loss Sharing and Commercial Impracticability, en 69 Minn. L. Rev. pp. 471-519.

Treitel, Guenter (2004): Frustration and Force Majeure, $2^{\text {nd }}$ edition (London, Sweet \& Maxwell Limited), 673 pp.

Vogenauer, Stefan y KleINHEISTERKAMPF, Jan (2009): Commentary on the UNIDROIT Principles of International Commercial Contracts (Oxford, Oxford U.P.), 1319 pp.

White, James J. and Peters, David A. (2001-2002), “A Footnote for Jack Dawson”, in 100 Mich. L. Review, pp. 1954-1979.

ZweIGERT, Konrad y KÖTZ, Hein (1998): An introduction to comparative law, $3^{\text {a }}$ ed., (Oxford, Clarendon Press), 714 pp.

\section{NORMAS CITADAS}

Código Civil alemán (Bürgerliches Gesetzbuch - BGB)

Código Civil de Chile

Código Civil francés (Code Civil)

Código Civil holandés (Burgerlijk Wetboek - BW)

Uniform Commercial Code

\section{JURISPRUDENCIA CITADA}

ADT Security Services Inc. v Premier Home Protection Home Inc., Colo. App. 2007, 181 P. 3d. 288. 
Aluminium Co. of America v. Essex Group, Inc., 499 F. Supp. 53 (W.D. Pa. 1980).

Canal de Craponne, Civ. 6 March 1876, DP 1876.I.197.

Cass. com, 3 November 1992, “arrêt Huard”, D. 1995, Somm. p. 85, note D. Ferrier.

Cass. com. 24 November 1998, "arrêt Chevassus-Marge”, D. 1999, IR p. 9.

Cass. civ. 16 March 2004, D. 2004 Somm. p. 1754, nota Denis Mazeaud.

Cass. com, 3 October 2006, D. 2007 n 11, Somm., p. 765, nota D. Mazeaud.

CA Nancy $2^{\text {nd }}$ Ch. Com. 26 September 2007, La Semaine Juridique No. 20, 14 May 2008, p. 29.

City of LaFollette v. LaFollette Water, Light \& tel. Co., 252 F. 762 (6 ${ }^{\text {th }}$ Cir. 1918).

Corte Suprema, 10 de enero de 1925, Revista de Derecho y Jurisprudencia, t. 23, sec. 1, pág. 423.

Ehredt Underground Inc. v. Commonwealth Edison Co. 848 F. Supp. 797 (N.D.Ill. 1994) at 814 .

Electricité de France c/ Shell Française CA Paris, $1^{\text {st }}$ Ch. A. 28 September 1976, La Semaine Juridique 1978, No 18.810, n. Jean Robert.

Gaz de Bourdeaux (C.E., 30 mars 1916).

Guillermo Larrain Vial con Serviu región Metrpolitana, Corte de Apelaciones de Santiago, once de noviembre de 2006, Número identificador LexisNexis: 35663.

ICC Award No. 7365/FMS (May 5, 1997).

ICC Award No. 9479 (Feb. 1999).

In re Westinghouse Elec. Corp. Uranium Contracts Litig., 517 F. Supp. 440 (E.D. Va. 1981; 312 S.E.2d 765 (W. Va. 1984).

Iowa Electric Light \& Power Co. v. Atlas Corp. 467 F. Supp. 129 (N.D. Iowa 1978), revised on other grounds, 603 F.2d 1301 ( $8^{\text {th }}$ Cir. 1979).

Japhe v. A-T-O Inc., 481 F2d 366 (5 ${ }^{\text {th }}$ Cir. 1973).

Kuwait v. American Independent Oil Company (Aminoil), March 24, 1982, reproducido en 21 I.L.M 976, 1014 (1982).

Louisiana Power \& Light Co. v. Allegheny Ludlum Industries, Inc., 517 F.Supp. 1319 (D.C.La., 1981).

McGinnis v Cayton, 312 S.E.2d 765 (W. Va. 1984).

Mineral Park Land Co. v. Howard, 172 Cal. 289, 156 P. 458 (1916).

Missouri Pub. Serv. Co. v Peabody Coal Co., 583 S.W. 2d 721 at 725 (Mo.App.1979), cert. denied. 444 U.S. 865, 100 S.Ct. 135, 62 L.Ed.2d 88.

Nichols v. Shelard National Bank, 294 N.W.2d 730 (Minn. 1980).

SAS Novacarb c/ SNC Socoma, CA Nancy $2^{\text {nd }}$ Ch. Com. 26 September 2007, SAS

Novacarb c/ SNC Socoma, La Semaine Juridique No. 20, 14 May 2008, at 10091, n.

Marie Lamoureux.

Unihealth v. U.S. Healthcare Inc., 14 F. Supp. 2d 623 (D.N.J. 1998).

Walford v. Miles [1992] 1 All ER 453, House of Lords.

Willard v. Tayloe, 75 U.S. (8 Wall.) 557 (1869);

Wintershall A.G. v. Gov't of Qatar, 28 ILM 795 at 814, 841 (1989). 


\section{DOCUMENTOS EN FORMATO ELECTRÓNICO}

Rapport du groupe de travail de la Cour de cassation Sur l'avant-projet de réforme du droit des obligations et de la prescription, 15 juin 2007; disponible en http:// www.courdecassation.fr/institution_1/autres_publications_discours_2039/discours_2202/travail_cour_10699.html (fecha de consulta: 13 de julio de 2009).

Projet de réforme du droit des contrats (Projet de la Chancellerie) disponible en http:// www.dimitri-houtcieff.fr/files/projet_droit_des_contrats_blog8_2_.pdf. (fecha de consulta: 13 de julio de 2009).

Ante-Proyecto para la reforma del Derecho de Obligaciones y de la Prescripción (Avantprojet Catala) disponible en http://www.henricapitant.org/sites/default/files/ Version_espagnole.pdf (fecha de consulta: 13 de julio de 2009). 